\title{
Surdez e sexualidade: Uma análise a partir das representações sociais de universitários surdos
}

\section{Deafness and sexuality: An analysis from the social representations of deaf university students}

\section{Sordera y sexualidad: Un análisis a partir de las representaciones sociales de universitarios sordos}

\author{
Valéria Maria Azevedo Guimarães* \\ Universidade Federal de Sergipe - UFS, São Cristóvão, Sergipe, Brasil
}

Fábio Santos**

Centro Universitário AGES - UniAGES, Paripiranga, Bahia, Brasil

Bruno Felipe de Santana Santos***

Centro Universitário AGES - UniAGES, Paripiranga, Bahia, Brasil

\section{Joilson Pereira da Silva****}

Universidade Federal de Sergipe - UFS, São Cristóvão, Sergipe, Brasil

\begin{abstract}
RESUMO
O objetivo do presente estudo foi analisar as representações sociais dos surdos universitários acerca da sexualidade. Esta pesquisa teve como aporte teórico a Teoria das Representações Sociais (TRS), que possibilita compreender a sexualidade, além do aspecto individual, elucidando a função do saber compartilhado. Tratou-se de uma pesquisa descritiva, com abordagem qualitativa, realizada com cinco universitários surdos que foram entrevistados de forma individual, em Língua Brasileira de Sinais (Libras) e por meio de um roteiro semiestruturado. Utilizou-se o Software IRAMUTEQ para a análise dos dados mediante a Classificação Hierárquica Descendente (CHD). Observou-se que as representações sociais da sexualidade dos participantes estão ancoradas no cuidado com a saúde sexual, no futuro profissional e nas relações amorosas, nas relações com a comunidade surda e com os familiares. Com isso, foi identificado que os participantes tiveram preocupação com a afetividade, o bem-estar, a atividade sexual e a satisfação em seus relacionamentos. No entanto, percebe-se a necessidade de desmistificar a temática entre os jovens surdos para que esses desenvolvam a sexualidade com autonomia.
\end{abstract}

Palavras-chave: representação social, sexualidade, universitários, surdo.

\section{ABSTRACT}

This study aimed to analyze the social representations of the deaf people about sexuality. This research had as theoretical contribution the Theory of Social Representations (TSR), which makes possible to understand the 
sexuality, be sides the individual aspect, elucidating the function of shared knowledge. It was a descriptive research, with a qualitative approach, carried out with five deaf students who were interviewed individually, in Brazilian Sign Language (BSL), through a semi-structured script. The IRAMUTEQ Software was used for the analysis of data using the Descending Hierarchical Classification (DHC). It was observed that the social representations of the participants' sexuality are anchored in the care with sexual health, in the professional future and in the amorous relations, in the relations with the deaf community and with the relatives. The study identified that the participants were concerned of affectivity, well-being, sexual activity and satisfaction in their relationships. However, it is necessary to demystify the theme among deaf young people so that they can develop their sexuality with autonomy.

Keywords: social representation, sexuality, undergraduates, deaf.

\section{RESUMEN}

El objetivo del presente estudio es analizar las representaciones sociales de los sordos acerca de la sexualidad. Esta investigación tuvo como aporte teórico la Teoría de las Representaciones Sociales (TRS), que posibilita comprender a la sexualidad, además del aspecto individual, elucidando la función del saber compartido. Se trató de una investigación descriptiva, con abordaje cualitativo, realizada con cinco universitarios sordos que fueron entrevistados de forma individual, en Lengua Brasileña de Señales (Libras), por medio de un itinerario semiestructurado. Se utilizó el software IRAMUTEQ para el análisis de los datos mediante la Clasificación Jerárquica Descendente (CJD). Se observó que las representaciones sociales de la sexualidad de los participantes están ancladas en el cuidado con la salud sexual, en el futuro profesional y en las relaciones amorosas, en las relaciones con la comunidad sorda y con los familiares. Con eso, fue identificado que los participantes tuvieron preocupación por la afectividad, el bienestar, la actividad sexual y la satisfacción en sus relaciones. Sin embargo, se percibe la necesidad de desmitificar la temática entre los jóvenes sordos para que éstos desarrollen la sexualidad con autonomía.

Palabras-clave: representación social, sexualidad, universitarios, sordos.

O ensino superior, paulatinamente, é conquistado pelas pessoas surdas. A recente inserção dos surdos nas universidades é proveniente de múltiplos fatores, sendo que, o reconhecimento da língua de sinais, da educação bilíngue para os surdos e das políticas de inclusão são alguns deles (Bisol, Valentini, Simioni, \& Zanchin, 2010). Devido às dificuldades de comunicação nos âmbitos familiar, escolar e social, alguns surdos podem deparar-se com estas barreiras também no ensino superior. Assim, a presença do intérprete é necessária para mediar o diálogo entre o surdo e o ouvinte. Dessa forma, percebe-se que a língua de sinais exerce um papel fundamental no processo de aprendizagem dos surdos, os possibilitando a interação social, compartilhar a sua cultura e adquirir o conhecimento de diferentes conteúdos (Oliveira \& Pôrto, 2014).

Os estudos sobre a cultura e a língua dos surdos são temas que ganharam espaço nas pesquisas científicas sobre a surdez, 
entretanto, outras temáticas deveriam ser abordadas, como é o caso da sexualidade dos surdos (Lebedeff, 2010). Segundo Melo e Santana (2005), a sexualidade faz parte da formação do ser humano, sendo considerada uma temática que tem a participação do contexto sociocultural. A sexualidade humana é um assunto explorado na mídia. No entanto, continua desconhecido e vinculado a tabus e mitos (Marques, Chedid, \& Eizerik, 2008). Glat (2004) afirma que semelhanças são encontradas na sexualidade dos jovens surdos e ouvintes, porém, o que difere são o acesso às informações e os preconceitos existentes acerca das expressões da sexualidade.

A vulnerabilidade provocada pela dificuldade em acessar informações sobre saúde sexual também gera riscos de gravidez não programada (Klein \& Formozo, 2007) e negligência na prevenção de Infecções Sexualmente Transmissíveis (ISTs) (Aldana, 2012). A falta de informações torna as pessoas surdas mais vulneráveis a abusos, inclusive sexuais e a serem ludibriadas, uma vez que não saberiam lidar com essas situações por falta de recursos pessoais (Klein \& Formozo, 2007, Trejo, 2005).

A ausência de uma comunicação efetiva na família gera os obstáculos comunicacionais e os empecilhos no acesso às informações (Ribeiro, 2017), que são responsáveis por interferir no desenvolvimento salutar da sexualidade dos jovens surdos (Aldana, 2012, Mineiro, 2010). A educação sexual, segundo Coutinho e Barros (2001), geralmente é indicada pela sociedade como papel da família. Todavia, há falhas ou omissões na transmissão das informações para os jovens. Em relação aos surdos, Job (2004) mostra as oportunidades de acesso às informações limitadas, a resistência dos familiares em viabilizar a educação sexual e o desconhecimento de colegas sobre o assunto, fatores que aumentariam a probabilidade do repasse errôneo destas informações, como contribuintes para 0 acesso restrito às informações referentes a essa temática.

Ademais, Glat (2004) assinala a necessidade de espaços que promovam o diálogo sobre o assunto em questão com o objetivo de possibilitar o desenvolvimento salutar da sexualidade desses sujeitos. Com a ausência de informações e do conhecimento na base familiar, recai sobre as instituições o dever de educar sobre a sexualidade. Todavia, é frequente observar que as instituições de ensino fornecem informações voltadas para aspectos fisiológicos e anatômicos através das disciplinas de ciências ou biologia, não havendo oportunidades para debater a sexualidade de forma ampla entre os jovens (Coutinho \& Barros, 2001). É importante que os programas de educação sexual sejam desenvolvidos de acordo com as características do seu público (Abreu, Silva, \& Zuchiwschi, 2015), o que exigiria o uso da língua de sinais para a educação dos surdos.

Em relação aos pontos mencionados até aqui, os surdos brasileiros estão amparados por diferentes dispositivos legais e políticos voltados 
a assegurar e impor ao Estado, à sociedade e à família a necessidade de garantir direitos constitucionais também às pessoas com deficiência, como a educação e a sexualidade, segundo a Lei Brasileira de Inclusão da Pessoa com Deficiência (Lei n. 13.146, 2015), assegurar o pleno exercício de direitos individuais e sociais, como indicado na Política Nacional para a Integração da Pessoa Portadora de Deficiência (Decreto n. 3.298, 1999), favorecer a inclusão social mediante a reabilitação da capacidade funcional e do desempenho, proteger a saúde e prevenir agravos ao surgimento de deficiências, conforme a Política Nacional de Saúde da Pessoa Portadora de Deficiência (Brasil, 2008), e promover, proteger e assegurar que as pessoas com deficiência possam usufruir de todos os direitos humanos e liberdades fundamentais aos seres humanos de modo pleno e equitativo com dignidade, de acordo com a Convenção sobre os Direitos das Pessoas com Deficiência (Brasil, 2012).

Esses e outros dispositivos surgiram de mobilizações e reivindicações. O percurso histórico dos surdos apresenta paridade com o que Magaldi (2011) expõe sobre as lutas populacionais que agregam em sua caminhada as exclusões e as adversidades no intuito de galgarem espaços igualitários, livres dos preconceitos e discriminações, que são centrais nas discussões acadêmicas e no movimento social. Esse autor acrescenta que as representações sociais podem "contribuir para uma maior compreensão do pensamento e da realidade social desses grupos" (p. 34). Outrossim, Moscovici (2011) destacou que a realidade social e suas práticas possibilitam a criação das representações sociais.

As representações sociais (RS) colaboram com a formação da realidade por meio das relações do indivíduo e do seu grupo com um objeto social, o que auxilia na interpretação, tomada de decisão e no posicionamento diante da realidade social (Jodelet, 2001). Isto pode ser percebido no estudo de Cambra (1996), quando retratou as representações sociais elaboradas por universitários ouvintes que descreveram os surdos como inseguros, reservados, imprudentes, impulsivos e nervosos, destacando que estas representações poderiam ter participação na imagem que os surdos constroem sobre si. Com esta perspectiva, Chaves e Silva (2013) e Almeida e Santos (2011) afirmaram que as RS permitem que o indivíduo compreenda e explique a realidade em que está inserido por meio da elaboração de conhecimentos novos. Desta forma, o presente estudo tem por objetivo analisar as representações sociais dos surdos acerca da sexualidade. 


\section{Método}

\section{Participantes}

Participaram do estudo cinco surdos, dos quais três foram do sexo masculino e dois do sexo feminino, usuários da Língua Brasileira de Sinais (Libras), matriculados em uma instituição do ensino superior. A idade dos participantes variou de 25 a 45 anos, possuindo uma média de idade de 33 anos $(D P=8,12)$, sendo que a média de idade entre os homens foi de 37,6 anos $(D P=7,02)$ e, entre as mulheres, 26 anos $(D P=1,41)$. Os entrevistados não utilizavam prótese auditiva, moravam com os familiares, tinham pais ouvintes e eram os únicos surdos da família. Quatro participantes informaram que o uso de Libras com os seus familiares não é aprofundado, pois estes não têm conhecimento suficiente da língua, o que torna necessário a utilização de outras estratégias (gestos, escrita, por exemplo) para efetivar a comunicação entre eles. Salienta-se que os participantes dessa pesquisa estão identificados a partir de nomes fictícios, conforme a resolução no 510/2016, garantindo, assim, o sigilo da amostra. O perfil dos participantes é apresentado na Tabela 1.

Tabela 1

Perfil dos Entrevistados

\begin{tabular}{lcc}
\hline Participantes & Estado civil & Comunicação familiar \\
\hline José & Solteiro & Oralização, leitura labial e Libras \\
Augusta & Solteira & Datilologia, gestos e Libras \\
Nicolas & Solteiro & Oralização, gestos e escrita \\
Amanda & Solteira & Libras, escrita e gestos \\
André & Solteiro & Libras \\
\hline
\end{tabular}

\section{Instrumentos}

As representações sociais dos universitários surdos sobre a sexualidade foram investigadas através de um roteiro individual de entrevista semiestruturado. Este versava sobre os dados pessoais dos participantes (idade, estado civil e a comunicação familiar), além de possuir 26 itens com perguntas relacionadas ao conhecimento da sexualidade, das relações afetivas, da autoimagem, das fontes de informações, dos métodos contraceptivos e das Infecções Sexualmente Transmissíveis. $O$ instrumento abordou questões como: "Peço para que você me conte tudo o que você acha importante e que pensa sobre sexualidade para os surdos", "Para você como deveria ser um relacionamento afetivo?", "Você se preocupa com a sua aparência? Por quê?", "Quais outros métodos contraceptivos que você conhece?". 
Anterior à coleta de dados, foi necessário adaptar o roteiro de entrevista do Português para Libras. Para isso, o roteiro passou pela avaliação de um grupo formado por quatro juízes ouvintes, seguido por uma intérprete de Libras. Por fim, foi realizado um estudo piloto com quatro estudantes surdos com o perfil semelhante ao da amostra final, com o objetivo de avaliar a compreensão das perguntas pelos estudantes e finalizar a sua construção.

\section{Procedimento}

Quanto ao presente estudo, trata-se de uma pesquisa qualitativa de cunho descritivo. As entrevistas foram realizadas em uma instituição do ensino superior. Os integrantes foram selecionados através da amostragem por conveniência. Inicialmente, foram explicados para os participantes, de forma individual, os objetivos da pesquisa, a ausência de respostas certas ou erradas, a garantia do sigilo e da participação voluntária através de um vídeo em Libras, produzido por uma intérprete, semelhante ao documento original do Termo de Consentimento Livre e Esclarecido (TCLE), com uma das duas vias assinadas entregue à pesquisadora e a outra aos participantes. As entrevistas foram conduzidas em língua de sinais pela pesquisadora e foram gravadas por câmera de vídeo, com duração aproximada de uma hora. Dois intérpretes realizaram a tradução das entrevistas da Libras para a Língua Portuguesa. Salienta-se que o presente estudo foi aprovado pelo Comitê de Ética em Pesquisa Envolvendo Seres Humanos (CEP) 83390118.6.0000.5546, sob o número do parecer 2.659.827.

\section{Análise dos dados}

O tratamento dos dados foi realizado pelo software IRAMUTEQ Interface de $R$ pour lês Analyses Multidimensionnelles de Textes et de Questionnaires. O IRAMUTEQ é considerado um programa informativo que possibilita diferentes análises textuais. A análise escolhida foi a Classificação Hierárquica Descendente (CHD), que permite encontrar o conteúdo lexical dos segmentos de textos através de um esquema hierárquico de classes (Camargo \& Justo, 2013).

\section{Resultados e Discussão}

O corpus investigado por meio da Classificação Hierárquica Descendente foi constituído por cinco textos, divididos em 486 segmentos de texto (ST), com aproveitamento de 373 ST $(76,75 \%)$. Emergiram 17.209 ocorrências, sendo 1.992 formas distintas e 406 com uma ocorrência. Além disso, os dados foram classificados em 
cinco classes temáticas, divididos em dois subgrupos e as 10 primeiras palavras de cada classe foram selecionadas e estão expostas na Figura 1. O dendograma contém as palavras expressas com sua frequência e seu qui-quadrado e seguirá a mesma ordem disponibilizada pelo IRAMUTEQ. A classe 5 é geradora das outras classes e se encontra no primeiro subgrupo, seguida da classe 5. Adicionalmente, as demais classes ( 1,3 e 4$)$ pertencem ao segundo subgrupo.

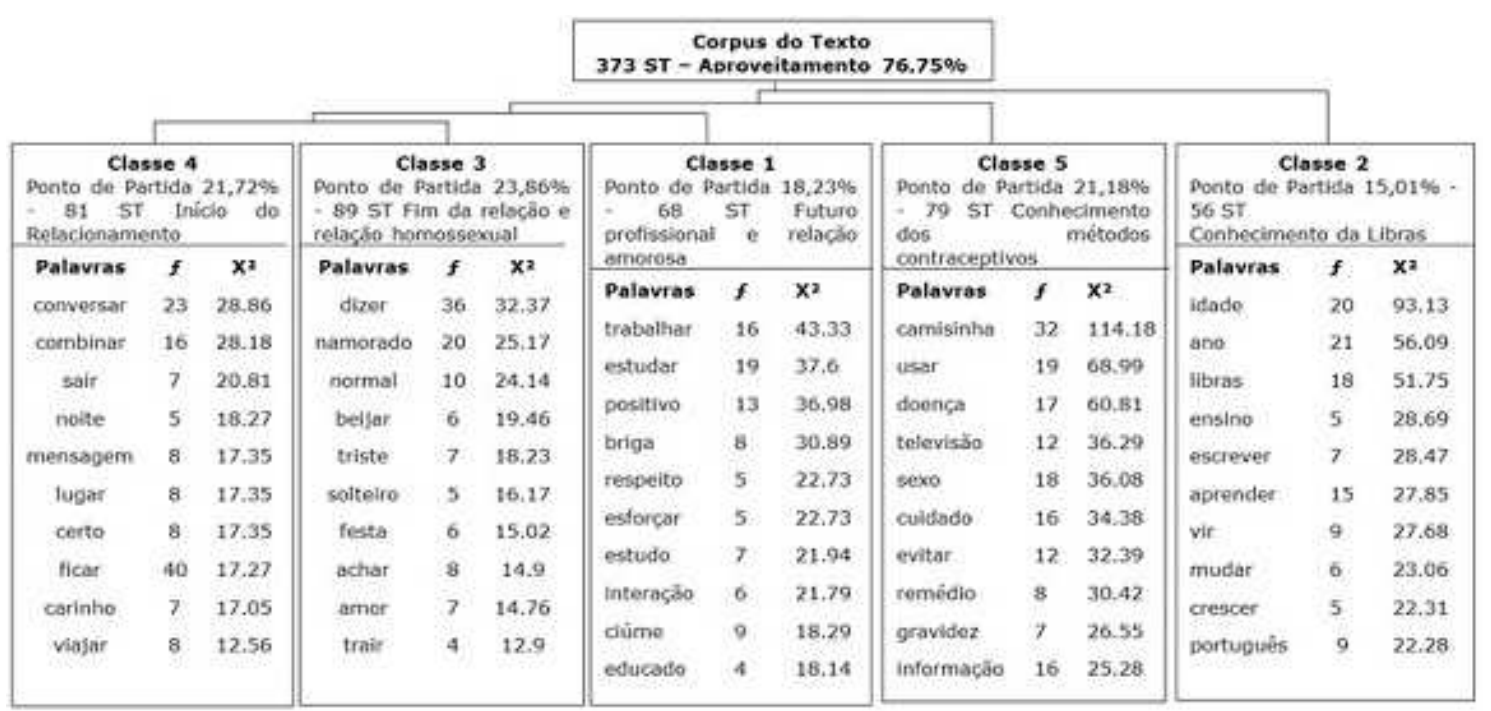

Figura 1. Dendograma da Classificação Hierárquica Descendente

Esta análise mostrou que as representações sociais da sexualidade dos universitários surdos pesquisados estão ancoradas no cuidado com a saúde sexual (classe 5), no futuro profissional, nas relações amorosas (classe 1) e nas relações com a comunidade surda e com familiares (classe 2, 3 e 4 ).

\section{Classe 2 - "Conhecimento da Libras"}

A classe 2 foi considerada a menor do dendograma, por representar $15,01 \%$ dos segmentos de texto analisados. Esta classe reúne conteúdos referentes à trajetória escolar dos discentes, ao aprendizado da língua de sinais, às dificuldades na comunicação e à importância da família.

Expressões como "idade", "ano", "libras" e "ensino" demarcaram o percurso escolar dos discentes entrevistados, o acesso tardio à Libras e a dificuldade de terem o intérprete em sala de aula. Isto pode ser percebido no extrato de Amanda: "... eu tinha mais ou menos 9 anos de idade, foi quando eu comecei a aprender a Libras. Estudei a quarta e quinta séries em uma escola inclusiva e não tinha intérprete, depois fui para sala de recursos e a professora tinha o conhecimento da Libras". Adicionalmente, os participantes informaram sobre a 
importância da comunidade surda para o aprendizado de Libras, como abordado por Nicolas: "... aprendi a Libras com mais ou menos 14 ou 15 anos. Fui aprendendo a Libras junto com outros surdos. Quando eu estudava não tinha professores que sabiam a Libras e a gente se comunicava por gestos".

Outras expressões associadas a essa classe são "escrever", "aprender", "crescer" e "português". Isto pode ser percebido no extrato de Amanda: "... a família toda oralizando e eu lá sem entender nada. Isso é muito ruim. Meu irmão conversa um pouco comigo, se precisar escrevo também. Com os meus primos eu converso um pouco por gestos, com as minhas tias eu converso através do português escrito, com a minha família eu converso pouco". É notório que essas expressões apontaram para as dificuldades na comunicação entre o surdo e sua família, sendo necessário ao surdo aprender a se comunicar por meio dos gestos e da escrita.

Além disso, observou-se que apesar da escassa comunicação entre os surdos e seus familiares, os participantes demonstraram afeto e salientaram a importância da família para o desenvolvimento pessoal. Isto foi apontado por José: "... a minha família me orienta muito, hoje eu consigo ver o lado positivo. A minha família me orienta para que o meu lado positivo cresça". Outrossim, os participantes informaram que quando iniciam uma relação, avisam que são surdos e começam a se comunicar através do português escrito e por gestos, mas caso a relação se prolongue, eles ensinam a Libras.

Os dados da classe 2, referentes à trajetória escolar dos discentes e ao aprendizado da língua de sinais, condizem com o estudo de Silva e Silva (2016), que informaram que o desenvolvimento escolar do discente surdo precisa de atenção devido às características linguísticas e culturais distintas dos demais alunos. Ademais, a língua de sinais é essencial para o desenvolvimento salutar da pessoa surda. Gesueli (2006) e Skliar (1999) salientaram a importância da escola bilíngue por proporcionar o contato das pessoas surdas com a língua de sinais e com outros surdos, o que contribui para a construção da identidade e do conhecimento da cultura surda.

Em relação às dificuldades na comunicação e a importância da família salientadas na classe 2, Behares (1996), Bisol, Bremm e Valentini (2010) e Carvalho e Santos (2016) ressaltaram o predomínio das pessoas ouvintes na sociedade e o frequente pertencimento dos surdos à família de pais ouvintes, o que ocasionam barreiras linguísticas devido ao predomínio da comunicação oral. Entretanto, Brito e Dessen (1999) informaram que, mesmo havendo menor interação entre pais ouvintes e filhos surdos, proveniente das dificuldades comunicacionais, é fundamental o contato dos pais com os seus filhos para emergir o sentimento de segurança na prole. Kelman e Faria (2007) complementaram que as mães de surdos 
impulsionam o desenvolvimento do infante surdo e promovem a inclusão e seu bem-estar.

\section{Classe 5 - "Conhecimento dos métodos contraceptivos"}

Esta classe representou $21,18 \%$ dos segmentos de texto analisados e envolveu temáticas acerca dos meios de prevenir as Infecções Sexualmente Transmissíveis e evitar a gravidez não programada, além das fontes em que adquiriam informações sobre a temática da sexualidade.

Os vocábulos "camisinha", "usar", "doença", "cuidado", "evitar", "remédio" e "gravidez" representam o cuidado com a saúde sexual e foram evidenciados nos seguintes trechos: "...é importante usar a camisinha porque no futuro pode evitar a gravidez não programada ou ficar doente. Tem os comprimidos e a injeção que protegem também" (Amanda), "...as pessoas podem pegar doenças através do sexo e passar para mim as doenças, então ele sabe que no sexo temos que usar a camisinha. É importante usar" (Augusta). Os participantes citaram o preservativo masculino como o mais utilizado, seguido pelo anticoncepcional em pílula e o injetável.

Salienta-se que os universitários entrevistados demonstraram preocupação em relação à prevenção, porém foram relatados alguns motivos para não utilizar o preservativo: confiança no(a) parceiro(a), contestação pessoal ou do(a) parceiro(a), a relação sexual de curta duração e não ter o preservativo no momento da relação sexual. Segue um extrato: "...eu uso a camisinha, mas se eu namorar e com o tempo perceber que ela é fiel, eu não uso a camisinha. Se eu terminar e começar outro relacionamento eu passo a usar a camisinha" (André).

Nesta perspectiva, os dados da classe 5 são semelhantes ao que Moreira (2016) ressalta: a temática da sexualidade é constantemente descrita no âmbito social pela ótica do biológico-funcional, associada à maternidade e aos órgãos sexuais. Em relação aos métodos contraceptivos, Alves e Lopes (2008) tiveram em sua amostra adolescentes universitários e perceberam que 0 preservativo masculino teve destaque na primeira relação sexual e foi considerado o método de mais uso. Adicionalmente, os universitários citaram o esquecimento do preservativo como um dos principais motivos para não o usar durante o ato sexual. Outro estudo também indicou o preservativo como o método mais citado entre os rapazes e pelas moças, seguido pelo anticoncepcional oral (Teixeira, Knauth, Fachel, \& Leal, 2006). O não uso do preservativo foi apontado por Figueiredo (2009) em sua pesquisa com universitários que informaram o vínculo e a fidelidade com o(a) parceiro(a) como um modo de prevenir doenças. 
Ainda na classe 5 foi observado que as palavras "televisão", "sexo" e "informação" indicaram o acesso às informações sobre a temática da sexualidade pelos participantes. Percebeu-se que a televisão, seguida pelas conversas informais com amigos, professores (período escolar), namorado(a), médico e pesquisas individuais foram as fontes de informações evidenciadas pelos participantes. Os discentes informaram sentir dificuldade em acompanhar os conteúdos passados na mídia por conta das legendas - ou por serem rápidas, ou por eles terem dúvidas no português escrito - e pela inexistência do intérprete na tela.

Tais dados estão em conformidade com o estudo de Louro (2008), em que ela retratou a constante exposição e a influência que a mídia, a publicidade, as novelas e a internet exercem sobre o ser humano. Isto também foi evidenciado no estudo de Lacerda (2004), quando a televisão, através dos programas, das reportagens ou campanhas educativas, foi considerada a fonte de informação mais citada entre os pesquisados. Entretanto, Henrique (2017) salienta a importância que as campanhas educativas possuem e a necessidade destas serem acessíveis para a comunidade surda. Arruda (1992) e Melo e Santana (2005) identificaram uma significativa influência dos amigos ou de grupos na aquisição do conhecimento sobre a sexualidade.

\section{Classe 1 - "Futuro profissional e relação amorosa"}

Esta classe representou $18,23 \%$ dos segmentos de texto analisados e retratou as representações sociais focadas no futuro profissional e nas relações amorosas, o que pode ser percebido no seguinte trecho: "... primeiro estuda, conclui os estudos e depois pode namorar. Antes precisa conhecer seu desenvolvimento, trabalhar, fazer uma faculdade, ter comunicação, para depois namorar com confiança e depois você casa. A sua vida será bem melhor" (Amanda). Expressões como "trabalhar", "estudar", "positivo" e "esforçar" demonstram a preocupação dos discentes com o desenvolvimento profissional, sendo necessários os estudos e a inserção na atividade laborativa para obter independência financeira e, se for o caso, formar uma família.

Os termos "respeito" e "interação", na classe 1 , referem-se a comportamentos que são necessários para que o relacionamento seja duradouro e de confiança. Entretanto, os vocábulos "ciúme" e "briga" foram apontados pelos participantes como descabidos para uma relação íntima. O fragmento a seguir ilustra isso: "...eu não gosto de brigas e conflitos, precisa ter o respeito e a confiança pelo outro, cada um segue seu caminho, na sua profissão, com seus grupos de amizades, mas sempre se respeitando" (José).

Em relação ao futuro profissional citado na classe 1, pode-se perceber o crescente número de surdos ingressando nas universidades 
brasileiras e, segundo o Ministério da Educação, no ano de 2017, o número de pessoas surdas que se matricularam em cursos de graduação foi de 2.138 (Brasil, 2018). A universidade é um ambiente geralmente constituído por adultos jovens e que proporciona expectativas, adaptações, autonomia e novas relações interpessoais, distintas do ambiente escolar anterior. A adaptação a essa nova fase irá depender da história do discente, de características pessoais e de suas habilidades (Ferreira, Almeida, \& Soares, 2001). A surdez e a inserção profissional foram estudadas por Magaldi (2011) através das representações sociais dos universitários surdos e duas subcategorias foram destacadas: "Orgulho surdo - O surdo é capaz" e "Desenvolvimento profissional sem mudanças salariais". Estas categorias indicaram o reconhecimento dos surdos sobre a sua capacidade e inserção no âmbito laboral, além de fortalecer a categoria dos trabalhadores surdos.

As representações sociais focadas na relação amorosa apontadas na classe 1 corroboram resultados encontrados no estudo de Aldana (2012) sobre as representações sociais da saúde sexual. Foi evidenciado o cuidado com o corpo, o medo de doenças e o prazer sexual como representações dos adolescentes surdos, fluentes na língua de sinais colombiana. A educação, o amor afetivo e as relações convencionais pertenciam aos adolescentes surdos que utilizavam a língua castelhana oral. Outra semelhança encontrada foi no estudo de Ribeiro (2011) sobre as relações afetivas de jovens surdas, que apontaram a fidelidade como primordial para a relação amorosa. Vieira, Nóbrega, Arruda e Veiga (2016) ressaltaram em seu estudo sobre as representações sociais das relações sexuais de mulheres que a afetividade foi apontada como essencial para a atividade sexual.

\section{Classe 3 - "Fim da relação e relação homossexual"}

Nesta classe foram representados $23,86 \%$ dos segmentos de texto analisados. Além disso, englobou temas como causas de término da relação, sentimentos gerados pelo término e a relação homossexual. As palavras "dizer", "namorado", "beijar", "festa" e "trair" estão associadas aos comportamentos do(a) parceiro(a) que podem induzir o término da relação amorosa. Amanda abordou isso: "...o segundo namorado só queria estar em festas. Eu não tenho vontade, eu não gosto dessas coisas. Ele dizia que eu podia dormir na casa dele e eu disse para ele ter calma, apenas tínhamos um mês de namoro". Salienta-se que a palavra "namoro" também descreve a relação homossexual e a não aceitação da família. Esse excerto demonstra isso: "...meu pai é bem desconfiado porque eu não tenho namorada, nunca apareci com uma mulher, sempre solteiro, então os meus pais desconfiam. Não penso em falar para os meus pais que sou homossexual, é difícil" (Nicolas). 
O fim da relação e os sentimentos que emergem com o término foram expressos nas palavras "triste", "solteiro", "achar" e "amor", como é percebido a seguir: "...eu sofri muito com o término do namoro, porque eu gostava muito dele. Passei um mês sofrendo bastante, mas depois minha mãe disse para eu parar com isso. Depois, com o tempo, foi passando, mas eu fiquei muito triste" (Amanda).

Os dados desta classe concordam com Leary, Springer, Negel, Ansell e Evans (1998), quando afirmaram que na relação romântica podem ocorrer transgressões, e com Finkel, Rusbult, Kumashiro e Hannon (2002), ao considerarem a relação extraconjugal e a incompatibilidade de ideias como possíveis causas de intrigas. 0 relacionamento romântico de adolescentes surdos do sexo masculino foi estudado por Jhai (2017), que buscou entender os impactos do grupo de aconselhamento no ambiente escolar. Inicialmente, os alunos apresentaram déficits de interação social e de vocabulário emocional. Após a intervenção grupal, os participantes compreenderam que os relacionamentos românticos perpassam o amor, gênero e casamento e melhorias foram apontadas em suas relações. Na pesquisa de Rodrigues e Fernandes (2017) foi identificado que os jovens buscam o amor, o respeito e a confiança em seus relacionamentos amorosos. A relação homossexual é evidenciada no estudo de Abreu et al. (2015) com surdos homossexuais que salientaram a homossexualidade das pessoas surdas como não compreendida pela sociedade, por envolver dúvidas, preconceitos e mitos sobre as vivências afetivo-eróticas.

\section{Classe 4 - "Início do relacionamento"}

Representou $21,72 \%$ dos segmentos de texto analisados. Diferente da classe anterior, nesta são expressas as estratégias e os comportamentos necessários para conseguir iniciar uma relação. Os termos "conversar", "combinar", "sair" e "mensagem" foram salientados como fundamentais para conhecer o outro, como é percebido a seguir: "...ficamos conversando pelo facebook, marcamos para tomar sorvete, passear, marcamos alguma coisa à noite, conversamos para saber se gostamos da pessoa e depois começamos a namorar" (Amanda). Vale destacar que além do contato presencial, os entrevistados citaram as redes sociais e os aplicativos de mensagens - em que o uso pode ser por texto ou vídeo-chamada como ferramentas que favorecem a comunicação com amigos ou futuros pretendentes.

Em correspondência com a pesquisa de Silva Neto, Mosmann e Lomando (2009), a busca do parceiro ideal é uma das particularidades do relacionamento amoroso. Estas buscas podem ser potencializadas pela influência exercida pela mídia e pelas tecnologias 
e repercutir no início e no término das relações em um curto espaço de tempo. Além disso, a internet é considerada uma telecomunicação que possibilita diferentes relacionamentos entre as pessoas e, com o surgimento dos chats, o indivíduo pode iniciar uma conversa de forma sigilosa e, a depender do interesse, pode emergir uma relação amorosa (Dela Coleta, Dela Coleta, \& Guimarães, 2008).

Nesta perspectiva, Fitz-Gerald, Fitz-Gerald e Williams (1978) destacaram a educação sexual como fundamental para a aquisição de conhecimento e para subsidiar as decisões que favoreçam a identidade sexual, prevenção e satisfação do sujeito. Obnial (2008) e Pablo-Santos (1991) complementaram que esta educação pode se basear em temáticas como as estruturas e funções corporais, as relações humanas, responsabilidades e satisfação sexual. Adicionalmente, as informações acerca da temática em questão devem ter início na infância e ter continuidade nas demais fases do desenvolvimento.

\section{Considerações Finais}

Por meio da análise das cinco classes, o presente estudo evidenciou que os participantes da pesquisa possuíam representações sociais sobre a sexualidade ancoradas no cuidado da saúde sexual, no futuro profissional, nas relações amorosas, nas relações com a comunidade surda e com familiares. Isto posto, foi identificado que os surdos pesquisados têm preocupação com a afetividade, como bem-estar, com a atividade sexual e com a satisfação dos surdos em seus relacionamentos.

Outro aspecto sinalizado pelos universitários foi a barreira na comunicação, por conta do desconhecimento da Libras pelos familiares e da maior parte da sociedade, o que pode gerar informações restritas sobre variados aspectos sociais, em especial a sexualidade. Além disso, a televisão, seguida pelas conversas informais com amigos e professores - no período escolar- com o(a) namorado(a), médico e pesquisas individuais foram salientados pelos universitários como essenciais para a troca de conhecimento acerca da sexualidade, além de destacarem a comunidade surda como fundamental para o desenvolvimento pessoal e social.

No entanto, foi possível perceber dificuldades enfrentadas pelos participantes no que diz respeito à obtenção das informações sobre a sexualidade. Cabe salientar a importância da participação das famílias e da continuação da disseminação de informações sobre a sexualidade na fase adulta para ampliarem o conceito da sexualidade, com o intuito de desmistificar e abordar os anseios e dúvidas acerca desta temática e auxiliar no desenvolvimento salutar desses jovens. 
Os desafios encontrados neste estudo foram lidar coma inexistência do sinal em Libras para a palavra sexualidade, sendo necessária a datilologia desta palavra para o entendimento do entrevistado, a escassez de estudos referentes à sexualidade e surdez e a carência de instrumentos validados para a comunidade surda. Percebe-se, ainda, a importância de novas pesquisas com participantes surdos sobre essa temática que possam subsidiar a criação de políticas públicas que atendam à diversidade social.

\section{Referências}

Abreu, F. S. D., Silva, D. N. H., \& Zuchiwschi, J. (2015). Surdos e Homossexuais: A (Des)coberta de Trajetórias Silenciadas. Temas em Psicologia, 23(3), 607-620. doi:10.9788/TP2015.307

Aldana, J. C. (2012). Representaciones sociales de la salud sexual de adolescentes sordos y oyentes en la ciudad de Bogotá. Pensamiento Psicológico, 10(2), 35-47. Recuperado de http://www.scielo.org.co/pdf/pepsi/v10n2/v10n2a05.pdf

Almeida, A. M. O., \& Santos, M. F. S. (2011). A teoria das Representações Sociais. In C. V. Torres \& E. R. Neiva (Orgs.), Psicologia Social: Principais Temas e Vertentes (pp. 287-295). Porto Alegre: Artmed.

Alves, A. S., \& Lopes, M. H. B. M. (2008). Uso de métodos anticoncepcionais entre adolescentes universitários. Revista Brasileira de Enfermagem, 61(2), 170-177. doi: 10.1590/S0034-71672008000200005

Arruda, A. (1992). Sexualidade e informação: Recado dos jovens paraibanos. In V. Paiva (Org.), Em tempos de AIDS (pp. 139144). São Paulo: Sumus.

Behares, L. E. (1996, Setembro). Aquisição da linguagem e interações mãe ouvinte - criança surda. Anais do Seminário Repensando a Educação da Pessoa Surda, INES, Rio de Janeiro, RJ, Brasil.

Bisol, C. A., Valentini, C. B., Simioni, J. L., \& Zanchin, J. (2010). Estudantes Surdos no Ensino Superior: Reflexões sobre a Inclusão. Cadernos de Pesquisa, 40(139), 147-172. doi:10.1590/S0100-15742010000100008

Bisol, C. A., Bremm, E. S., \& Valentini, C. B. (2010). Blogs de adolescentes surdos: Escrita e construção de sentido. Revista Semestral da Associação Brasileira de Psicologia Escolar e Educacional, 14(2), 291-299. Recuperado de http://www.scielo.br/pdf/pee/v14n2/a11v14n2.pdf

Brasil. (1999). Decreto n. 3.298, de 20 de dezembro de 1999. Regulamenta a Lei no 7.853, de 24 de outubro de 1989, dispõe 
sobre a Política Nacional para a Integração da Pessoa Portadora de Deficiência, consolida as normas de proteção, e dá outras providências. Recuperado de http://www.planalto.gov.br/ccivil_03/decreto/D3298.htm

Brasil. (2008). Política Nacional de Saúde da Pessoa Portadora de Deficiência. Brasília: Ministério da Saúde.

Brasil. (2012). Convenção sobre os Direitos das Pessoas com Deficiência (4a ed.). Brasília: Secretaria de Direitos Humanos, Secretaria Nacional de Promoção dos Direitos da Pessoa com Deficiência. Recuperado de https://www.pessoacomdeficiencia.gov.br/app/publicacoes/con vencao-sobre-os-direitos-das-pessoas-com-deficiencia

Brasil. (2015). Lei n. 13.146, de 6 de julho de 2015. Institui a Lei Brasileira de Inclusão da Pessoa com Deficiência (Estatuto da Pessoa com Deficiência). Recuperado de http://planalto.gov.br/ccivil_03/_Ato20152018/2015/Lei/L13146.htm

Brasil. (2018). Ministério da Educação. Censo da educação superior 2017: divulgação dos principais resultados. Brasília: Diretoria de Estatísticas Educacionais. Recuperado de http://portal.mec.gov.br/docman/setembro-2018-pdf/97041apresentac-a-o-censo-superior-u-Itimo/file

Brito, A. M. W., \& Dessen, M. A. (1999). Crianças surdas e suas famílias: Um panorama geral. Psicologia: Reflexão e Crítica, 12(2), 429-445. doi:10.1590/S0102-79721999000200012

Camargo, B. V., \& Justo, A. M. (2013). IRAMUTEQ: Um software gratuito para análise de dados textuais. Temas em Psicologia, 21(2), 513-518. doi:10.9788/TP2013.2-16

Cambra, C. A. (1996). Comparative study of personality descriptors attributed to the deaf, the blind, and Individuals with no sensory disability. American Annals of the Deaf, 141(1), 24-28. doi:10.1353/aad.2012.0007

Carvalho, D. M., \& Santos, L. R. L. (2016). Pais ouvintes, filho surdo: Causas e consequências na aquisição da língua de sinais como primeira língua. Revista Sinalizar, 1(2), 190-203. Recuperado de https://www.revistas.ufg.br/revsinal/article/view/41493

Chaves, A. M. \& Silva, P. L. (2013). Representações Sociais. In L. Camino, A. R. R. Torres, M. E. O. Lima, \& M. E. Pereira (Orgs.), Psicologia Social: Temas e Teorias (pp. 299-349). Brasília: Technopolitik.

Coutinho, M. F. G., \& Barros, R. R. (2001). Adolescência: Uma abordagem prática (pp. 201-50). São Paulo: Atheneu.

Dela Coleta, A. S. M., Dela Coleta, M. F., \& Guimarães, J. L. (2008). $\mathrm{O}$ amor pode ser virtual? O relacionamento amoroso pela internet. Psicologia em Estudo, 13(2), 277-285. Recuperado de http://www.scielo.br/pdf/pe/v13n2/a10v13n2.pdf 
Ferreira, J. A., Almeida, L. S., \& Soares, A. P. C. (2001). Adaptação acadêmica em estudante do $1^{\circ}$ ano: Diferenças de gênero, situação de estudante e curso. PsicoUSF, 6(1), 1-10. doi: $10.1590 /$ S1413-82712001000100002

Figueiredo, M. M. O. (2009). Auto isolamento ou exclusão? As diferentes visões sobre surdos (Monografia de Especialização). Curso de Educação Especial, Faculdade de Santa Helena, Recife. Recuperado de http://www.suvag.org.br/arquivos/mmof.pdf

Finkel, E. J., Rusbult, C. E., Kumashiro, M., \& Hannon, P. A. (2002). Dealing With Betrayal in Close Relationships: Does Commitment Promote Forgiveness? Journal Of Personality \& Social Psychology, 82(6), 956-974. doi:10.1037//0022-3514.82.6.956

Fitz-Gerald, D., Fitz-Gerald, M. \& Williams, C. M. (1978). The sex educator: Who's teaching the teacher sex education? American Annals of the Deaf, 123(1), 68-72. doi:10.1353/aad.2012.0209

Gesueli, Z. M. (2006). Lingua(gem) e identidade: a surdez em questão. Educação \& Sociedade, 27(94), 277-292. doi:10.1590/S0101-73302006000100013

Glat, R. (2004). Saúde sexual, deficiência e juventude em risco. Relatório de consultoria técnica: educação sexual, sexualidade, juventude, deficiência, depoimentos, inclusão social. Rio de Janeiro: Banco Mundial.

Henrique, D. R. (2017). Língua de sinais brasileira: análise de campanhas do ministério da saúde na perspectiva da pessoa surda (Dissertação de Mestrado). Programa de Pós-Graduação em Ciências e Tecnologias em Saúde, Universidade de Brasília, Brasília, DF, Brasil.

Jhai, Zong-Ti. (2017). Impact of a romantic relationships counseling group project on deaf male adolescents in a deaf school. Sexuality Disability, 35(2), 185-206. doi:10.1007/s11195-0179481-0

Job, J. (2004). Factors involved in the ineffective dissemination of sexuality information to individuals who are deaf or hard of hearing. American Annals of the Deaf, 149(3), 264-273. doi:10.1353/aad.2004.0025

Jodelet, D. (2001). Representações sociais: Um domínio em expansão. In D. Jodelet, (Org.), As representações sociais. Rio de Janeiro: EDUERJ.

Kelman, C. A., \& Faria, C. B. (2007). Mães de surdos e suas percepções. In E. J. Manzini (Org.), Inclusão do aluno com deficiência na escola: os desafios continuam (pp. 187-200). Marília: ABPEE/FAPESP.

Klein, M., \& Formozo, D. P. (2007). Gênero e surdez. Reflexão e Ação, 15(1), 100-112. doi:10.17058/rea.v15i1.225

Lacerda, M. A. (2004). Adolescentes falando "daquilo": um estudo qualitativo das fontes de informação sobre sexualidade e saúde 
reprodutiva em duas escolas municipais de Betim, MG. In XIV Encontro Nacional de Estudos Populacionais, ABEP. Recuperado de

http://www.abep.org.br/publicacoes/index.php/anais/article/vie $w / 1316$

Leary, M. R., Springer, C., Negel, L., Ansell, E., \& Evans, K. (1998). The causes, phenomenology, and consequences of hurt feelings. Journal of Personality and Social Psychology, 74(5), 1225-1237. doi: 10.1037/0022-3514.74.5.1225

Lebedeff, T. B. (2010). Surdez e sexualidade: Uma discussão sobre a necessidade de empoderamento linguístico e acesso à informação. Anais do Encontro de Pesquisa em Educação da Região Sul - ANPEDSU, Universidade Estadual de Maringá, Maringá, Paraná, Brasil, 8. Recuperado de https://docplayer.com.br/13124540-Surdez-e-sexualidadeuma-discussao-sobre-a-necessidade-de-empoderamentolinguistico-e-acesso-a-informacao-tatiana-bolivar-lebedeffufpel.html

Louro, G. L. (2008). Gênero e sexualidade: Pedagogias contemporâneas. Pro-Posições, 19(2), 17-23. doi:10.1590/S0103-73072008000200003

Magaldi, J. C. M. (2011). Surdez e Inserção Profissional: representações sociais de universitários surdos (Dissertação de Mestrado). Universidade Estácio de Sá, Rio de Janeiro, RJ, Brasil.

Marques, F. Z. C., Chedid, S. B., \& Eizerik, G. C. (2008). Resposta sexual humana. Revista de Ciências Médicas, 17(3-6), 175-183. Recuperado de https://seer.sis.puccampinas.edu.br/seer/index.php/cienciasmedicas/article/viewFil e/755/735

Melo, A. S. A. F., \& Santana, J. S. S. (2005). Sexualidade: Concepções, valores e condutas entre universitários de biologia da UEFS. Revista Baiana saúde pública, 29(2), 149-159.

Mineiro, E. T. C. (2010). A sexualidade sob a ótica do jovem surdo (Monografia de Especialização). Universidade Federal de Santa Maria, Feira de Santana, BA, Brasil. Recuperado de https://repositorio.ufsm.br/handle/1/2721

Moreira, S. Z. (2016). A mulher surda e suas relações de gênero e sexualidade. In C. Skliar (Org.), A surdez: um olhar sobre as diferenças (8a ed.). Porto Alegre: Mediação.

Moscovici, S. (2011). Representações sociais: Investigações em psicologia social (8a ed.). Petrópolis, RJ: Vozes.

Obnial, I. (2008). A parent manual in teaching education to adolescents with mental retardation (Master of Arts thesis), University of the Philippines, Diliman, Cidade Quezon, Filipinas. 
Oliveira, K. K. F., \& Pôrto, C. M. V. (2014). Comunicação entre acadêmicos surdos e ouvintes na mediação da aprendizagem no ensino superior. Cadernos de Terapia Ocupacional UFSCar, 22(2), 335-345. doi:10.4322/cto.2014.055

Pablo-Santos, R. (1991). Manual on Sexuality for People with Disabilities. Quezon City: National Council on Disability Affairs.

Ribeiro, K. (2011). Sexualidade e gênero: Estudos das relações afetivas de jovens surdas de uma escola municipal de educação especial de São Paulo (Tese de Doutorado). Faculdade em Educação, Universidade de São Paulo, São Paulo, SP, Brasil.

Ribeiro, J. A. K. (2017). A lesbianidade e a surdez. Periodicus, 1(7), 179-191. doi:10.9771/peri.v1i7.21550

Rodrigues, D., \& Fernandes, A. M. (2017). Relacionamentos amorosos: Percepção e comportamentos dos jovens universitários. Revista da Mostra de Trabalhos de Conclusão de Curso, 1(1), 778-795. Recuperado de http://trabalhos.congrega.urcamp.edu.br/index.php/1tcc/article /view/1735/1596

Silva Neto, J. A., Mosmann, C. P., \& Lomando, E. (2009). Relações amorosas \& internet. São Leopoldo: Sinodal.

Silva, C. M. \& Silva, D. N. H. (2016). Libras na educação de surdos: O que dizem os profissionais da escola? Psicologia Escolar e Educacional, 20(1), 33-43. doi:10.1590/21753539/2016/0201917

Skliar, C. (1999). Apresentação: a Localização política da educação bilíngue para surdos. In C. Skliar (Org.), Atualidade da educação bilíngue para surdos (pp. 7-14). Porto Alegre: Mediação.

Teixeira, A. M. F. B., Knauth, D. R., Fachel, J. M. G., \& Leal, A. F. (2006). Adolescentes e uso de preservativos: As escolhas dos jovens de três capitais brasileiras na iniciação e na última relação sexual. Cadernos de Saúde Pública, 22(7), 1385-1396. doi: $10.1590 / S 0102-311 \times 2006000700004$

Trejo, M. T. (2005). La construcción de la sexualidad en adolescentes sordos y sordas. Archivos Hispanoamericanos de Sexología, 11(2), 203-218. Recuperado de http://www.culturasorda.org/wp-

content/uploads/2015/03/Tellez_Construcion_Sexualidad_adole scentes_sordos_2005.pdf

Vieira, K. F. L., Nóbrega, R. P. M., Arruda, M. V. S., \& Veiga, P. M. M. (2016). Representação social das relações sexuais: um estudo transgeracional entre mulheres. Psicologia: Ciência e Profissão, 36(2), 329-340. doi:10.1590/1982-3703001752013 


\section{Endereço para correspondência}

Valéria Maria Azevedo Guimarães

Universidade Federal de Sergipe - UFS

Cidade Universitária Professor José Aloísio de Campos

Avenida Marechal Rondon, s/n, 10 andar da didática 02, CEP 49100-000, São

Cristóvão - SE, Brasil

Endereço eletrônico: guimaraes.psicologa@gmail.com

\section{Fábio Santos}

Universidade Federal de Sergipe - UFS

Cidade Universitária Professor José Aloísio de Campos

Avenida Marechal Rondon, s/n, 10 andar da didática 02, CEP 49100-000, São Cristóvão - SE, Brasil

Endereço eletrônico: fbi-psico@hotmail.com

\section{Bruno Felipe de Santana Santos}

Centro Universitário AGES - UniAGES

Núcleo de Desenvolvimento Estruturante - Gabinete de Psicologia

Avenida Universitária, 23, Parque das Palmeiras, CEP 48430-000, Paripiranga - BA, Brasil

Endereço eletrônico: bruno_psico@yahoo.com.br

\section{Joilson Pereira da Silva}

Universidade Federal de Sergipe - UFS

Cidade Universitária Professor José Aloísio de Campos

Avenida Marechal Rondon, s/n, 10 andar da didática 02, CEP 49100-000, São Cristóvão - SE, Brasil

Endereço eletrônico: joilsonp@hotmail.com

Recebido em: $12 / 12 / 2018$

Reformulado em: 29/03/2019

Aceito em: 13/05/2019

\section{Notas}

* Psicóloga, Especialista em Terapia Cognitivo-Comportamental - IMEA. Mestra e Doutoranda em Psicologia pela Universidade Federal de Sergipe.

** Psicólogo. Mestre em Psicologia (Universidade Federal de Sergipe). Preceptor e supervisor de estágio no Centro Universitário AGES (UniAGES).

*** Psicólogo, Mestre e Doutorando em Saúde e Ambiente. Professor e coordenador do Curso de Psicologia no Centro Universitário AGES (UniAGES).

**** Psicólogo com Pós-Doutorado pela Universidade Autônoma de Barcelona. Professor do Departamento de Letras/Libras da Universidade Federal de Sergipe.

Financiamento: Capes.

Este artigo de revista Estudos e Pesquisas em Psicologia é licenciado sob uma Licença Creative Commons Atribuição-Não Comercial 3.0 Não Adaptada. 